Research Article

\title{
Effect of Compressive Strain Rate on Microstructure and Mechanical Properties of 7050 Aluminium Alloy
}

\author{
Qiang Shen $\mathbb{D},{ }^{1}$ Luochuang Huang, ${ }^{2}$ Yan $\mathrm{Li}^{2},{ }^{2}$ Kang $\mathrm{Yu},{ }^{1}$ and Dezheng Liu $\mathbb{D}^{2}$ \\ ${ }^{1}$ Department of Materials Engineering, School of Engineering, Huzhou University, Huzhou 313000, China \\ ${ }^{2}$ Department of Mechanical Engineering, Hubei University of Arts and Science, Xiangyang, Hubei 441053, China
}

Correspondence should be addressed to Dezheng Liu; liudezheng126@126.com

Received 5 July 2021; Revised 30 October 2021; Accepted 1 November 2021; Published 8 December 2021

Academic Editor: Kaushik Kumar

Copyright (c) 2021 Qiang Shen et al. This is an open access article distributed under the Creative Commons Attribution License, which permits unrestricted use, distribution, and reproduction in any medium, provided the original work is properly cited.

7050 aluminium alloy is a superior material used in the areas of aerospace and automobile manufacturing. In this work, homogeneous cast cylinder samples of 7050 aluminium alloy with size of $\Phi 80 \mathrm{~mm} \times 100 \mathrm{~mm}$ were compressed isothermally at $350^{\circ} \mathrm{C}$ with compressive strain rate of $0.1 \mathrm{~s}^{-1}, 1 \mathrm{~s}^{-1}$, and $10 \mathrm{~s}^{-1}$, respectively. The samples were then processed into standard tensile specimens, and then tensile testing was done by using the GL8305 universal testing machine. The grain sizes and fracture morphology were analyzed by the SEM observation and cellular automaton (CA) method. The effect of compressive strain rate on microstructure and mechanical properties of 7050 aluminium alloy was investigated. The results show the following. (1) Grain refinement occurred after compression. The grain sizes of the samples decrease with the decrease of compressive strain rate. The grain sizes in the radial edge and the axial center of the cylinder samples are the smallest. (2) The tensile strength and breaking elongation rate were improved when compared to the original alloy. The mechanical properties of samples compressed with compressive strain rate of $0.1 \mathrm{~s}^{-1}$ are the best. (3) The fracture morphology of the samples shows that the fracture of the samples is ductile fracture. The sizes and depths of dimples increased with the decrease of grain sizes.

\section{Introduction}

7050 aluminium alloy is widely used in the fields of aerospace, automobile manufacturing, high-speed rail manufacturing, and shipping industry due to its high strength, good toughness, excellent corrosion resistance, and lightweight [1-4]. Hot extrusion is one of the main plastic forming process methods for manufacturing 7XXX series aluminium alloy with high performance [5-7]. The parameters of hot extrusion, such as extrusion speed, processing temperature, extrusion pressure, and so on, largely affect the properties of aluminium alloy.

In the past decades, research studies have been done to investigate microstructure evolution and mechanical properties of aluminium alloy processed by the hot compression process. The microstructure of aluminium alloys usually experiences dynamic recrystallization (DRX) during the hot extrusion process. Chen et al. [8] investigated the microstructural evolution under compression tests over a wide range of strain rates. Work hardening deceases with the increase of strain rate. Dynamic recrystallization with grain refinement and phase transition occurred during compression. Li et al. [9] found that the fraction of DRX increased with decrease of strain rate, and Huang et al. [10] found that the percentage of DRX increased with the rise of temperature. Zhao et al. [7] found that the recrystallization mechanism during isothermal compression changed from continuous dynamic recrystallization to discontinuous dynamic recrystallization mechanism as the strain rate decreased from $10^{-3} \mathrm{~s}^{-1}$ to $5 \times 10^{-6} \mathrm{~s}^{-1}$. Cardoso et al. [11] compared the grain sizes and hardness of 7050 aluminium alloy process with equal channel angular pressing (ECAP) at room temperature and $150^{\circ} \mathrm{C}$. The sample pressed at $150^{\circ} \mathrm{C}$ has more refined grains and larger hardness. Yunzhong et al. [12] investigated the grain evolution at different parts of the 7050 aluminium alloy cylinder sample and the result shows the deformation of grain at the central part get larger when the strain increased while the grains becomes smaller and 
more homogeneous. However, the evolution of grains associated with strain distribution at different parts of cylinder samples during hot compression is much more complicated. Thus, the evolution of grains of cylinder aluminium alloys needs to be researched in greater detail. The mechanical properties of alloy are largely related to the microstructure, such as the grain shape, and the type and orientation of texture. Branco et al. [13] researched the effect of strain ratio on cyclic deformation behaviour of 7050 aluminium alloy. The material exhibited a cyclic strain softening behaviour, and the microstructure shows mainly elongated grains aligned with the rolling direction with a certain degree of recrystallization. Wei et al. [14] found that the yield strength in the center of the cylinder sample with a large grain size is higher than that at the edge with the smaller grain size in the thickest section of the cylinder. This is because the effect of texture on the yield strength overweighed the refinement strengthening, where copper-orientated $(\{112\}<111>)$ deformation texture with better yield strength dominated the center area and cube-orientated $(\{112\}<111>)$ recrystallized texture dominated at the edge. Few investigations have studied the tensile strength and tensile fracture combined with evolution of microstructure of compressed 7050 aluminium alloy. Additional research studies are important to explore the relationship between mechanical behaviours and microstructure of 7050 aluminium alloy resulted from hot compression during the tensile experiment.

In our work, 7050 aluminium alloy cylinder samples with size of $\varphi 80 \mathrm{~mm} \times 100 \mathrm{~mm}$ were isothermally compressed with three strain rates $\left(0.01 \mathrm{~s}^{-1}, 0.1 \mathrm{~s}^{-1}\right.$, and $\left.1 \mathrm{~s}^{-1}\right)$ at $350^{\circ} \mathrm{C}$. The total strain value of the compression is 0.6 . The cylinder samples are then processed to standard tensile specimens at room temperature. Tensile testing was done by using the GL8305 universal testing machine. The microstructure and the grain evolution were observed via EBSD and simulated with the CA method. The effect of strain rate on alloy microstructure and mechanical properties was investigated. The fracture was characterized and analyzed.

\section{Mathematical Modelling}

2.1. Constitutive Model and Dynamic Recrystallization Model. The high-temperature rheological behaviour of 7050 aluminium alloy is not only related to the composition of chemical elements but also affected by the deformation temperature and strain rate. The Arrhenius model [15] is used to describe the high-temperature rheological behaviour of aluminium alloy in this work. It is mathematically expressed as follows:

$$
\dot{\varepsilon}=A[\sinh (\alpha \sigma)]^{n} \exp \left(-\frac{Q}{R T}\right),
$$

where $A, b$, and $n$ are material constants, which can be calculated via isothermal uniaxial tensile test, $\dot{\varepsilon}$ and $\sigma$ are the strain rate and the stress, $Q$ is the activation energy of deformation $(\mathrm{kJ} / \mathrm{mol}), T$ is the temperature $(\mathrm{K})$, and $R$ is the gas constant, which is $8.314 \mathrm{~J} /(\mathrm{mol} \cdot \mathrm{K})$.

Nucleation of dynamic recrystallization is a complicated process which usually occurs locally in the deformed matrix.
The decrease of dislocation density causes the decrease of free energy of the sample while formation of new intersurface between new crystal nuclei and the matrix leads to the increase of free energy [16].

The model of dynamic recrystallization can be expressed as follows:

$$
\begin{aligned}
d_{r e x} & =x_{1} d_{0}^{b_{1}} \varepsilon^{n_{1}} \dot{\varepsilon}^{m_{1}} \exp \left[\frac{Q_{1}}{R T}\right], \\
X_{d r x} & =1-\exp \left[-\beta_{d}\left(\frac{\varepsilon-x_{2} \varepsilon_{p}}{\varepsilon_{0.5}}\right)^{k_{d}}\right], \\
\varepsilon_{0.5} & =x_{3} d_{0}^{b_{2}} \varepsilon^{n_{2}} \dot{\varepsilon}^{m_{2}} \exp \left(\frac{Q_{2}}{R T}\right),
\end{aligned}
$$

where $x_{1}, x_{2}, x_{3}, b_{1}, b_{2}, n_{1}, n_{2}, m_{1}, m_{2}, \beta_{d}$, and $k_{d}$ are material constants in the recrystallization model, which can be obtained from isothermal uniaxial tensile test, $d_{0}$ is the original grain size of 7050 aluminium alloy (its value is $\sim 70 \mu \mathrm{m}), Q_{1}$ and $Q_{2}$ represent the activation energy of grain growth and the activation energy of recrystallization $(\mathrm{kJ} /$ $\mathrm{mol}), \varepsilon_{0.5}$ is the strain when volume fraction of dynamic recrystallization reaches $50 \%$, and $\varepsilon_{p}$ is peak strain of dynamic recrystallization which can be calculated by the following formula:

$$
\varepsilon_{p}=x_{4} d_{0}^{b_{3}} \dot{\varepsilon}^{m_{3}} \exp \left(\frac{Q_{3}}{R T}\right),
$$

where $x_{4}, b_{3}$, and $m_{3}$ are material parameters, which can be calculated by second derivative of the function between strain hardening rate and stress. For more details on the aforementioned parameters of 7050 aluminium alloy, the readers are referred to reference [17], and the values are shown in Table 1.

2.2. Cellular Automaton (CA) Method. Cellular automaton method is a mathematical model of dynamic system which is discrete in time and space. It consists of five fundamental concepts: cellular unit, cellular state, cellular neighbour type, cellular space, and cellular transition rules. The cellular unit is defined as $2.5 \mu \mathrm{m} \times 2.5 \mu \mathrm{m}$ square.

The cellular state contains the state variable $i$ and the direction variable $j$. The cellular unit is solid state if the variable $i=1$ and the cellular unit is liquid if $i=0$. The value of $j$ is any integer between $0-180$, and each integer represents a specific orientation. The cellular space is defined as a square cellular grid with cellular unit number of $400 \times 400$. Thus, the space size of cellular space is $1 \mathrm{~mm} \times 1 \mathrm{~mm}$ according to the cellular unit size of $2.5 \mu \mathrm{m}$. The state of the neighbouring cellular units at specific moment $t$ can be expressed as follows:

$$
\gamma_{C_{i}}^{t}=f\left(\gamma_{C_{1}}^{t-\Delta t}, \gamma_{C_{2}}^{t-\Delta t}, \gamma_{C_{3}}^{t-\Delta t}, \ldots, \gamma_{C_{k}}^{t-\Delta t}, \gamma_{C_{i}}^{t-\Delta t}\right),
$$

where $\gamma_{C_{i}}^{t-\Delta t}$ represents the state of the cellular unit at specific moment $t, C_{k}$ is the $K$ th neighbour of the cellular unit, $f$ is the functional relationship, and $\Delta t$ is the variation of time. 
TABLE 1: The value of parameters of the dynamic recrystallization model.

\begin{tabular}{cccccccccccccccccc}
\hline$x_{1}$ & $x_{2}$ & $x_{3}$ & $x_{4}$ & $b_{1}$ & $b_{2}$ & $b_{3}$ & $n_{1}$ & $n_{2}$ & $m_{1}$ & $m_{2}$ & $m_{3}$ & $\beta_{d}$ & $k_{d}$ & $\begin{array}{c}Q_{1} \\
(\mathrm{~kJ} / \mathrm{mol})\end{array}$ & $\begin{array}{c}Q_{2} \\
(\mathrm{~kJ} / \mathrm{mol})\end{array}$ & $\begin{array}{c}Q_{3} \\
(\mathrm{~kJ} / \mathrm{mol})\end{array}$ \\
\hline 125.8 & 0.491 & 0.00136 & 0.0255 & -0.00495 & -0.364 & 0.123 & 0 & 0 & -0.0103 & 0.192 & 0.0671 & 0.693 & 2.11 & 2311.0 & 13380.8 & 16844.7 \\
\hline
\end{tabular}

\section{Experiment and Simulation Method}

3.1. Materials and Experiment Method. The 7050 aluminium alloy was provided by Southwest Aluminium Group Co. Ltd. The alloy ingots were slowly heated to $470^{\circ} \mathrm{C}$ at the rate of $0.5^{\circ} \mathrm{C} / \mathrm{s}$ and were annealed for $24 \mathrm{~h}$. Then, alloy ingots were then water cooled to room temperature. The heat treatment process helped to preserve the homogenized structure and prevent element segregation near the grain boundary. After homogenization treatment, 7050 aluminium alloy ingots were processed to cylinder samples with size of $\Phi 80 \mathrm{~mm} \times 100 \mathrm{~mm}$. The chemical composition of the alloy was characterized by the PDA-5500S Shimadzu spectrum analyzer.

The chemical composition of the sample conforms to 7050 aluminium alloy according to the standard GB/T31901996, which is displayed in Table 2.

The single-pass compression test of the cylinder samples was done by using the thermal physics simulator Gleeble 1500 . Thermocouples were welded on the side of the samples to monitor and collect test temperatures. The compression tests were done by using the thermal physics simulator Gleeble 1500. The samples were heated to $350^{\circ} \mathrm{C}$ at a rate of $10^{\circ} \mathrm{C} / \mathrm{s}$ and annealed for $60 \mathrm{~s}$ to reduce anisotropy before compression. The cylinder samples were compressed at different rates $\left(0.1 \mathrm{~s}^{-1}\right.$, $1.0 \mathrm{~s}^{-1}$, and $10.0 \mathrm{~s}^{-1}$ ) until the total tensile strain reached 0.6 . The grains in the different parts of the cylinder samples were observed and compared with electron backscattering diffraction (EBSD). Standard tensile specimens were prepared from the cylinder samples according to standard of DB52/T 926-2014. These tensile specimens were taken from the central axis of the cylinder, and the sampling location is shown in Figure 1(a). The detailed size parameters of the standard tensile specimen are shown in Figure 1(b). Tensile testing was performed to examine the mechanical properties of these compressed samples.

The quasistatic tensile test of specimens was carried out on the GL8305 universal testing machine. The mechanical parameters: tensile strength and fracture derivation rate, were measured according to GB/T228.1-2010 [18]. The fracture was electrochemically polished with an electrolyte solution mixed with $10 \%$ perchlorate and $90 \%$ ethanol. The voltage, the current, and the time of electrolytic polishing are $26 \mathrm{~V}, 1.2 \mathrm{~A}$, and $4 \mathrm{~s}$, respectively. Then, the specimen was anodically coated with a solution which consists of $5 \mathrm{~mL}$ fluoroborate and $200 \mathrm{~mL}$ deionized water. The voltage, the current, and the time of coating are $25 \mathrm{~V}, 1.5 \mathrm{~A}$, and $50 \mathrm{~s}$. Then, the fracture was ultrasonically cleaned after electrochemical polishing and anodical coating. The fracture was observed by using the JSM6510 scanning electron microscope (SEM).

3.2. Finite Element Model. The thermal compression process and grain evolution of 7050 aluminium alloy cylinder were simulated in the software DEFORM 3D V6. The high-temperature rheological model of the material was assigned according to formula (1), and the dynamic recrystallization model was assigned according to formulas (2) (5). The cylinder rod was premeshed in the software Hypermesh 14.0. The mesh elements were mainly in a hexahedral shape, and the grids at the notch were locally densified. The total number of the grids was 36278 . The punch and the die were set as rigid bodies. The temperature was set at $350^{\circ} \mathrm{C}$. The die was fixed, and the punch moved at speeds of $1 \mathrm{~mm} / \mathrm{s}, 10 \mathrm{~mm} / \mathrm{s}$, and $100 \mathrm{~mm} / \mathrm{s}$, respectively. The punch stopped moving until the nominal strain reached 0.6 . The results of the previous step were imported into the postprocessing microstructure simulation module. The evolution of alloy grains during the tensile test was simulated via the cellular automaton (CA) method. The plastic damage and mechanism of grain evolution were investigated.

\section{Results and Discussion}

4.1. The Evolution of Microstructure. Figure 2 shows the grain images oriented at the axial center of the cylindrical sample. Figures 2(a)-2(d) show the grain structure photographed by EBSD technique, and Figures 2(e)-2(h) show the simulated grain structure derived from the CA simulation technique. Figure 2(e) shows undeformed grains of raw aluminium alloy with mean sizes of $\sim 70 \mu \mathrm{m}$. The structures in Figures 2(b), (c) and (d) indicate that the grains of the compressed samples were refined after plastic deformation. As shown in Figure 2(b), coarse grains of samples loaded with a strain rate of $0.01 \mathrm{~s}^{-1}$ were crushed. A large number of fine grains appeared both inside the grains and near the grain boundary, which showed equiaxed shape. It reflects that dynamic recrystallization was fully finished in this sample. The microstructure of samples processed with strain rate of $0.1 \mathrm{~s}^{-1}$ at $350^{\circ} \mathrm{C}$ (Figure 2(c)) reveals that a lot of coarse grains were squeezed. A small number of fine grains appeared near the boundary of coarse grains, suggesting that dynamic recrystallization partially happened. In Figure 2(d), fine grains nucleated near the grain boundaries of most of the grains. It indicates that the dynamic recrystallization was about to happen. Table 3 shows the statistic of mean grain size derived from the EBSD and CA simulation method. The data of Table 3 and the insets in Figure 2 indicate that the mean grain sizes simulated by CA are consistent with the results of the images taken by EBSD. The deviation of mean grain sizes between two ways is smaller than $5 \%$.

When the compressive rate is small, grain refinement in the alloy driven by the dynamic recrystallization mechanism can fully take place. The recrystallization process is attributed to sufficient degree of freedom for rotation and rearrangement of grain nuclei and subgrains [19]. When the compressive rate increases, there is low degree of freedom 
TABLE 2: The chemical composition of 7050 aluminium alloy (wt\%).

\begin{tabular}{lcccccccc}
\hline Chemical elements & $\mathrm{Zn}$ & $\mathrm{Cu}$ & $\mathrm{Mg}$ & $\mathrm{Zr}$ & $\mathrm{Ti}$ & $\mathrm{Si}$ & $\mathrm{Fe}$ & $\mathrm{Al}$ \\
\hline Actual values (wt\%) & 6.65 & 2.54 & 2.54 & 0.14 & 0.058 & 0.13 & 0.15 & $\mathrm{Remains}$ \\
GB/T3190-1996 & $5.7 \sim 6.7$ & $2.0 \sim 2.6$ & $1.9 \sim 2.6$ & $0.08 \sim 0.15$ & 0.06 & 0.12 & 0.15 & Remains \\
\hline
\end{tabular}

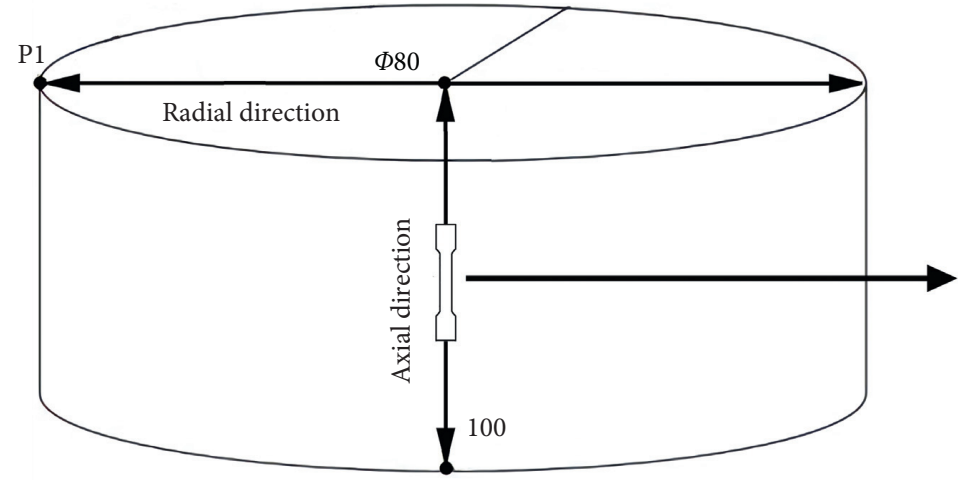

(unit: $\mathrm{mm}$ )

(a)

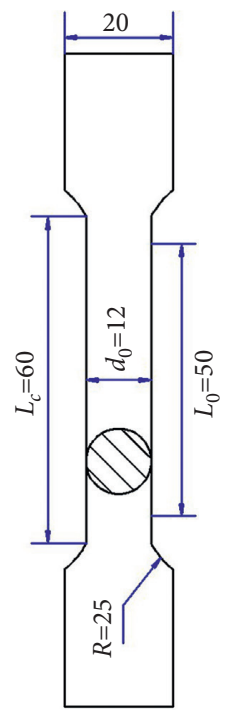

(b)

Figure 1: The sampling position (a) and the size diagram (b) of standard tensile specimen (mm).
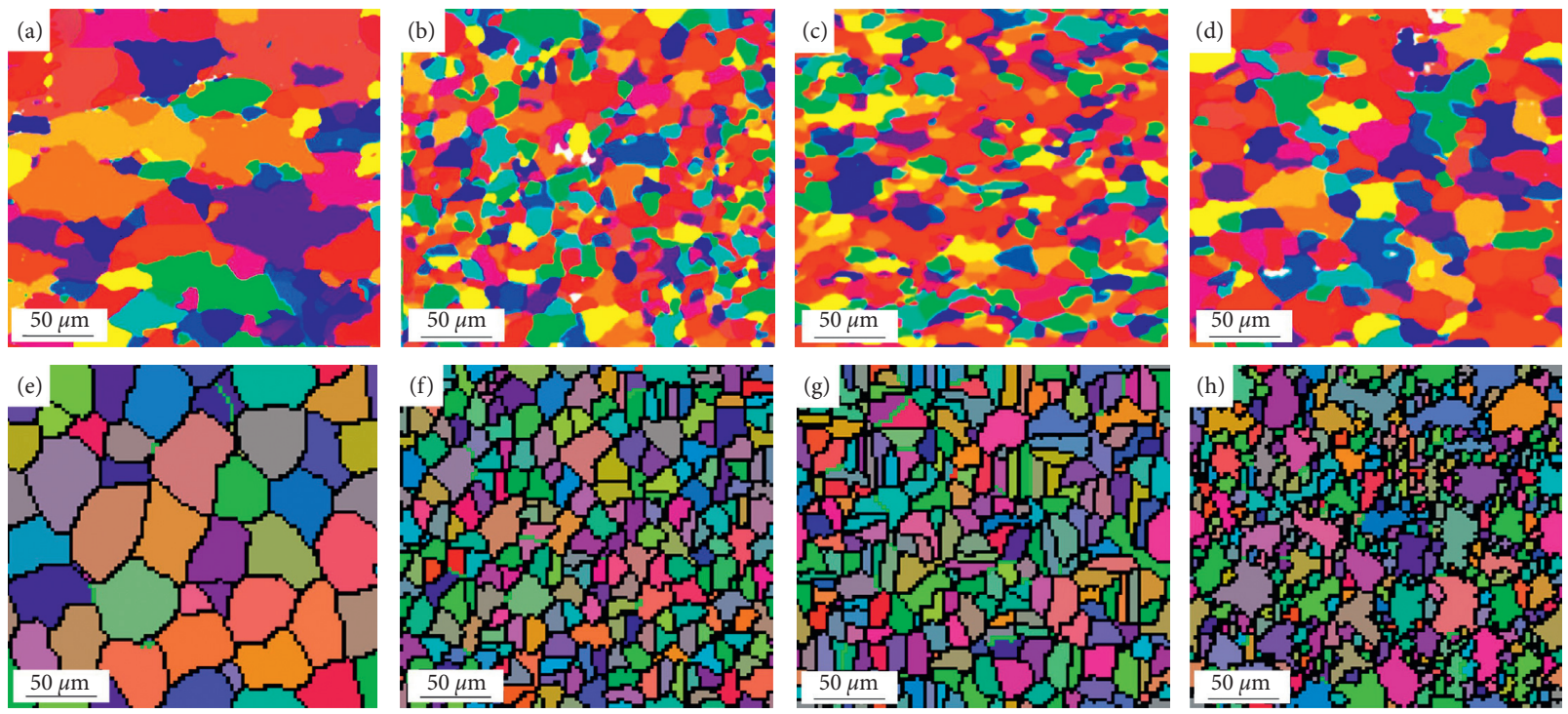

Figure 2: The grain images in the axial center of the cylindrical samples compressed at $350^{\circ} \mathrm{C}$ with (a) no strain rate (raw structure); (b) compressive strain rate of $0.01 \mathrm{~s}^{-1}$; (c) compressive strain rate of $0.1 \mathrm{~s}^{-1}$; (d) compressive strain rate of $1.0 \mathrm{~s}^{-1}$. The CA simulated microstructure of samples compressed at $350^{\circ} \mathrm{C}$ with (e) no strain rate; (f) compressive strain rate of $0.01 \mathrm{~s}^{-1}$; (g) compressive strain rate of $0.1 \mathrm{~s}^{-1}$; (h) compressive strain rate of $1.0 \mathrm{~s}^{-1}$.

for rotation and rearrangement of grain nuclei and subgrains. High dislocation density-induced work hardening mechanism dominates the evolution of inner structure while there is not enough time to trigger the dynamic recrystallization of grains. In consequence, grains with small sizes are only formed around the grain boundaries in the samples compressed with high rate, as shown in Figure 2(d). The refinement of alloy grains can be realized by decreasing the compressive rate to improve dynamic recrystallization effect.

Figure 3 shows the grain size distribution along the axial and the radial directions of the sample loaded with compressive strain rate of $0.01 \mathrm{~s}^{-1}$ at $350^{\circ} \mathrm{C}$. The strains and grain 
TABLE 3: The mean grain size from EBSD and CA simulation.

\begin{tabular}{lccc}
\hline Strain rate $(\mathrm{mm} / \mathrm{mm})$ & Mean grain size $(\mathrm{EBSD}, \mu \mathrm{m})$ & Mean grain size $(\mathrm{CA}, \mu \mathrm{m})$ & Deviation $(\%)$ \\
\hline 0 & 70 & 70 & - \\
0.01 & 25.6 & 24.5 & 4.3 \\
0.1 & 32.6 & 31.5 & 3.4 \\
1 & 44.8 & 42.6 & 4.9 \\
\hline
\end{tabular}

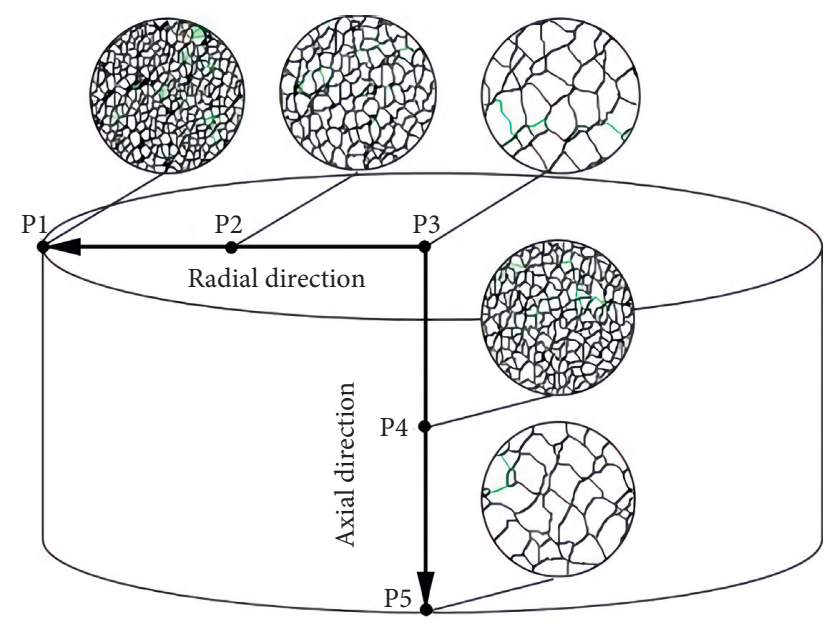

FIgURE 3: The grain size distribution of the cylinder sample with strain rate of $0.01 \mathrm{~s}^{-1}$ at $350^{\circ} \mathrm{C}$.

sizes of spots P1 P7 are analyzed. The image of upper surface shows that the grains at the edge of the surface are the finest. The grain size increased from the edge to the center along the radial direction. The value increases from $2.38 \mu \mathrm{m}$ to $50.3 \mu \mathrm{m}$. The axial change of grains indicates that the grain size increases from the cylinder center to both sides of the cylinder axially. This is because both sides of the sample were in contact with the punch and the die, respectively. The friction between the contact surfaces during plastic deformation obstructs the radial migration of atoms, which leads to the axial reduction of strain. The end face of the cylinder sample is a freely deformed surface with no obstruction of friction. Therefore, it migrates outside during the deformation. Furthermore, the local strain at the edge of upper and bottom surfaces of the sample also increased because of the "pull effect" from the end face of the cylinder. The strain distribution is shown by the coloured strain pattern of cylinder sample with strain rate of $0.01 \mathrm{~s}^{-1}$ at $350^{\circ} \mathrm{C}$ as shown in Figure 4. The sample in Figure 4 presents a bulge shape. The strain is the largest at the edge of the upper and bottom surfaces and at the center of the samples. The strain is the smallest at the center of the upper and bottom surfaces. The grain refinement is closely related to the strain distribution. The larger the strain is, the higher the grain refinement is.

Figure 5 shows the curve of strain vs. deformation time of the sample with compressive strain rate of $0.01 \mathrm{~s}^{-1}$ at $350^{\circ} \mathrm{C}$. Data of spots P1-P5 marked in Figure 5 were collected. The strain of P1 is 1.78 which is the largest of the alloy after deformation. The largest strain value of $\mathrm{P} 4$ after deformation is 1.64. The strains of P2, P3, and P5 show a similar curve as shown in Figure 5. Figure 6 shows the strain

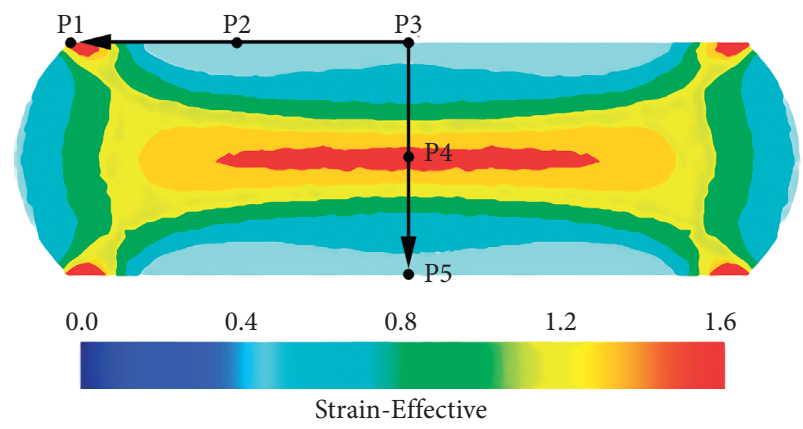

FIGURE 4: The coloured strain pattern of the cylinder sample with strain rate of $0.01 \mathrm{~s}^{-1}$ at $350^{\circ} \mathrm{C}$.

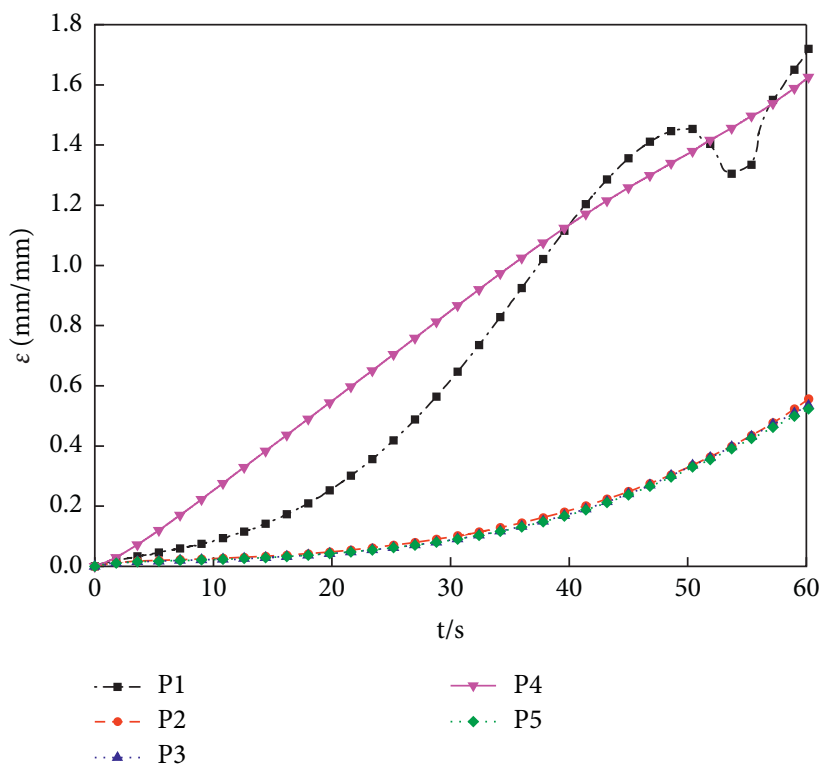

FIGURE 5: Curve of strain vs. deformation time of spots derived from Figure 4 (P1 P5).

distribution along the axial and radial directions. The radial direction takes the center of the circle on the upper surface as the origin point, and the axial direction takes the center of the cylinder as the origin point. The radial curve indicated that the strain of about $80 \%$ of spots kept a value of $\sim 0.5 \mathrm{~mm} /$ $\mathrm{mm}$. The strain along the axial direction decreases from the center to both sides evenly.

Figure 7 shows the grain size distribution along axial (Figure $7(\mathrm{a})$ ) and radial (Figure $7(\mathrm{~b})$ ) directions with different compressive strain rates. The distribution of grain sizes is in great agreement with distribution of strain. As shown in Figure 7(a), the grain sizes decreased from the 


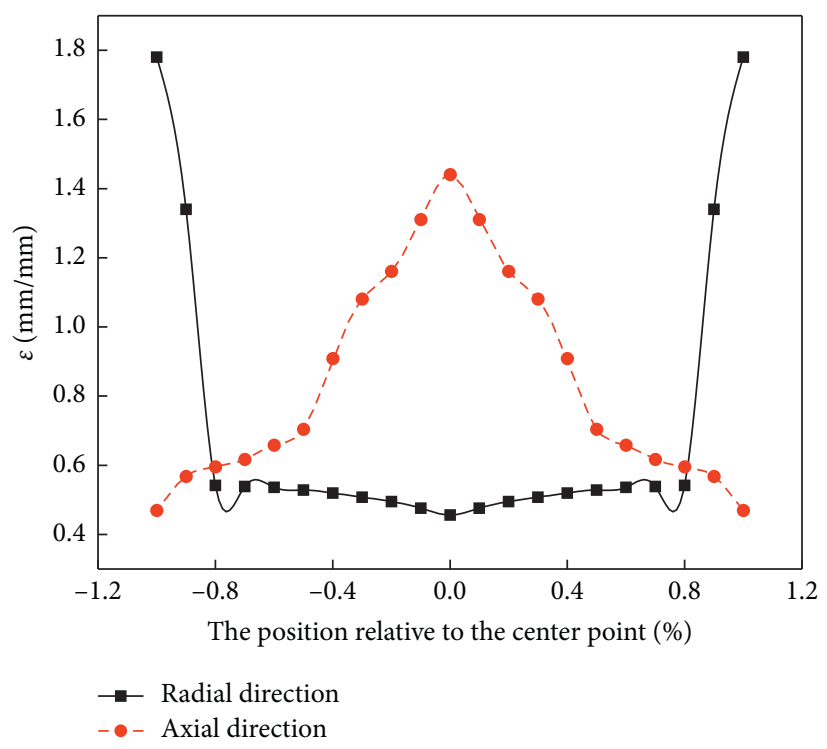

FIGURE 6: Strain deformation along axial and radial directions of the cylinder.

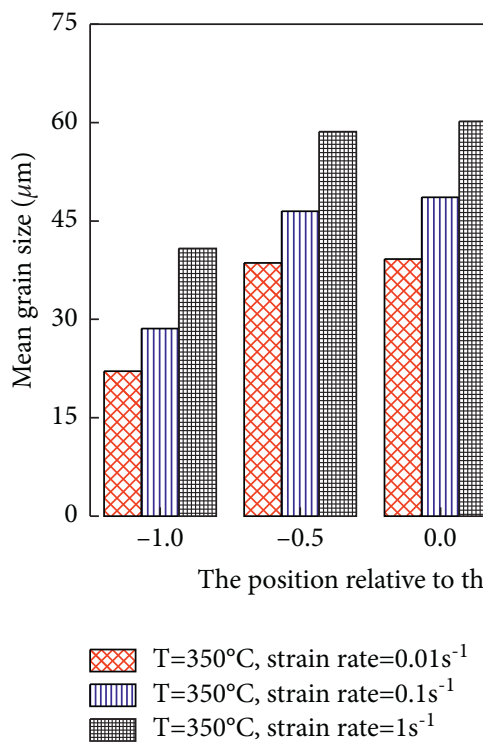

(a)

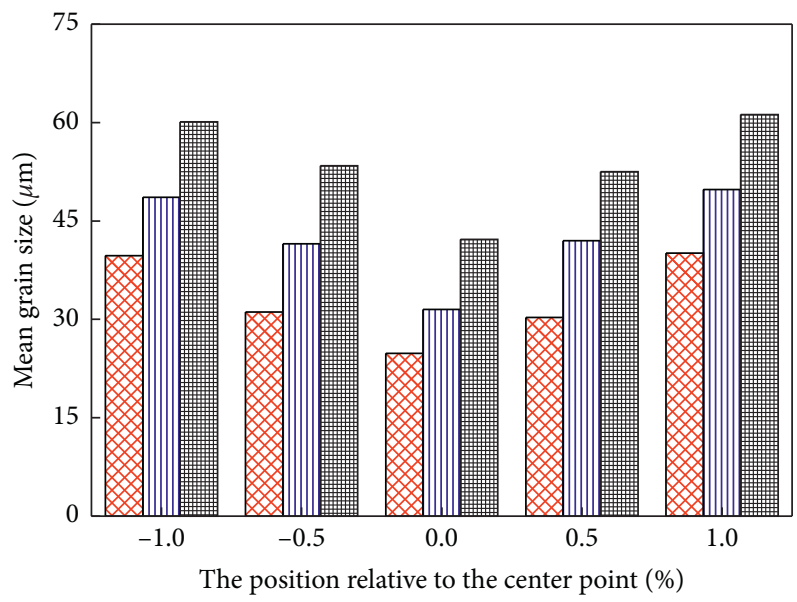

$\mathrm{T}=350^{\circ} \mathrm{C}$, strain rate $=0.01 \mathrm{~s}^{-1}$
$\mathrm{~T}=350^{\circ} \mathrm{C}$, strain rate $=0.1 \mathrm{~s}^{-1}$
$\mathrm{~T}=350^{\circ} \mathrm{C}$, strain rate $=1 \mathrm{~s}^{-1}$

(b)

Figure 7: The grain size distribution along radial (a) and axial (b) directions of the cylinder with different compressive strain rates.

center to the sides of cylinder radially. The grains sizes increased from the cylinder center to up and down surfaces axially as shown in Figure 7(b). The grain sizes of the sample with compressive strain rate of $0.01 \mathrm{~s}^{-1}$ were the smallest.

4.2. Mechanical Properties. True stress-strain curve of standard tensile samples was transformed by stress-strain curve obtained by using the universal testing machine GL8305. Figure 8 illustrates that the tensile strength and fracture elongation of sample subjected to the compression deformation both increased in different degrees. The tensile strength and fracture elongation rate of the raw tensile sample are $516 \mathrm{MPa}$ and 0.19 . The improvement of tensile strength and fracture elongation of samples compressed with strain rate of $0.01 \mathrm{~s}^{-1}$ is the highest. Values of tensile strength and fracture elongation are $660.1 \mathrm{MPa}$ and 0.26 , which were increased by $28.1 \%$ and $35.3 \%$ compared to the raw sample. The tensile strength and fracture elongation of the sample compressed with the strain rate of $0.1 \mathrm{~s}^{-1}$ increased by $13.6 \%$ and $30.0 \%$. The tensile strength and fracture elongation of the sample compressed with the strain rate of $1 \mathrm{~s}^{-1}$ increased by $10.1 \%$ and $10.0 \%$.

Tensile strength of the samples increased with the decrease of strain rate. Compression with smaller compress rate resulted in sufficient recrystallization and grain refinement. Refinement 


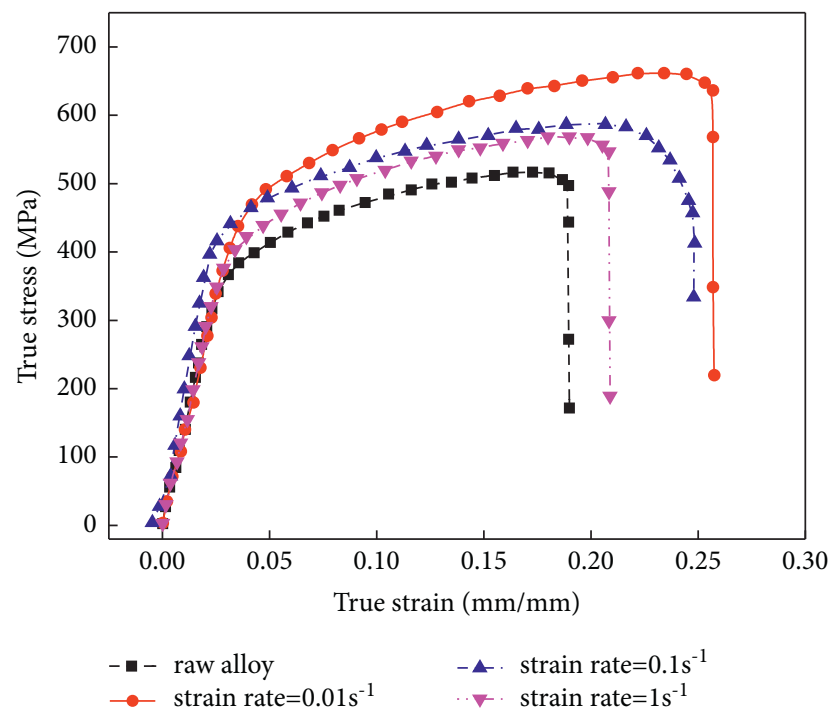

Figure 8: True stress-strain curve of standard tensile 7050 aluminium alloy samples.
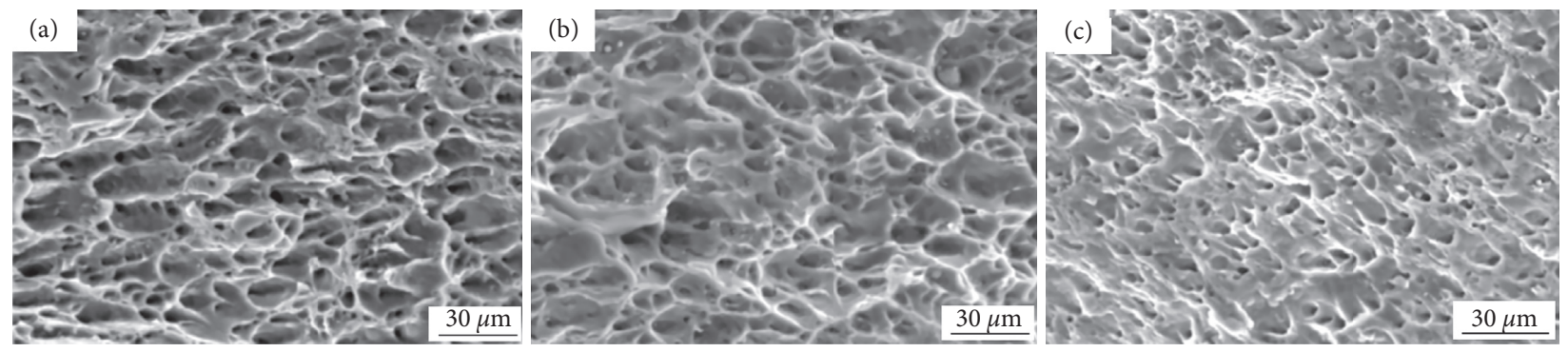

FIGURE 9: Fracture images of samples compressed with strain rates of (a) $0.01 \mathrm{~s}^{-1}$, (b) $0.1 \mathrm{~s}^{-1}$, and (c) $1 \mathrm{~s}^{-1}$.

strengthening is an efficient way to improve mechanical properties of aluminium alloys, which was also reported in other works $[20,21]$. Therefore, the improvement of the tensile strength of the compressed samples is mainly attributed to grain refinement, and this is in great agreement with the refinement degree of samples treated with different compressive strain rates.

Figure 9 shows the morphology of tensile fracture of the compression sample with different strain rates observed by SEM. It can be seen from Figure 9 that a large number of dimples were observed at the tensile fracture, indicating that 7050 aluminium alloy has good plasticity after thermal compression [22]. The dimples of the sample with strain rate of $0.01 \mathrm{~s}^{-1}$ were the largest and deepest. Small particles observed in the images were impurity precipitates. The dimples nucleated at the interface between the impurity precipitates and matrix grains and then grew up. Small dimples appeared at the edge of large dimples in the sample with strain rate of $0.1 \mathrm{~s}^{-1}$. The dimples were relatively shallow, and tearing ridges were formed on the fracture surface. The fracture morphologies of three specimens were in great agreement with the results of the tensile tests.

\section{Conclusion}

7050 aluminium alloy cylinder samples with size of $\Phi 80 \mathrm{~mm} \times 100 \mathrm{~mm}$ were isothermally compressed with three strain rates $\left(0.01 \mathrm{~s}^{-1}, 0.1 \mathrm{~s}^{-1}\right.$, and $\left.1 \mathrm{~s}^{-1}\right)$ at $350^{\circ} \mathrm{C}$. The cylinder samples were processed to standard tensile specimens at room temperature. Tensile testing was done by using the GL8305 universal testing machine. The grain evolution and fracture morphology were analyzed by the CA simulation method and SEM observation. The effect of compressive strain rate on alloy microstructure and mechanical properties was investigated. For 7050 aluminium alloy, the following conclusions can be drawn:

(1) Grain refinement occurred during the compression deformation of 7050 aluminium alloy. The sample with strain rate of $0.01 \mathrm{~s}^{-1}$ achieved the smallest grain size. The analysis of sample with strain rate of $0.01 \mathrm{~s}^{-1}$ reveals that the grain size decreased radially from the center of the upper surface. The grain size increased axially from the center of the cylinder to both sides.

(2) The tensile strength and fracture elongation of 7050 aluminium alloy were improved after compressive deformation. The tensile strength and fracture elongation of sample with strain rate of $0.01 \mathrm{~s}^{-1}$ increased to $660 \mathrm{MPa}$ and 0.26 , which increased by $28.1 \%$ and $35.3 \%$.

(3) Dimples were formed on the fracture section. Dimples on the fracture section of samples with strain rate of $0.01 \mathrm{~s}^{-1}$ were the largest and the deepest. 


\section{Data Availability}

No data were used to support this study.

\section{Conflicts of Interest}

The authors declare that they have no conflicts of interest.

\section{Acknowledgments}

This study was supported by the Huzhou Public Welfare Project of Technology Application (2021GZ03), the Natural Science Foundation of Hubei Province (2020CFB284), and the Scientific Research Project of Education Department of Hubei Province (D20202601).

\section{References}

[1] F. Song, X. Zhang, S. Liu, N. Han, and D. Li, "Anisotropy of localized corrosion in 7050-T7451 Al alloy thick plate," Transactions of Nonferrous Metals Society of China, vol. 23, no. 9, pp. 2483-2490, 2013.

[2] E. A. Starke and J. C. Williams, "Progress in structural materials for aerospace systems," Acta Materialia, vol. 51, no. 19, pp. 5775-5799, 2003.

[3] G. Peng, Z. T.. Xiaoqing, G. Zhi, and C. Li, "Refinement mechanism Research of Al3Ni phase in Ni-7050 alloy," Rare Metal Materials and Engineering, vol. 42, no. 1, pp. 6-13, 2013.

[4] B. Zhou, B. Liu, and S. Zhang, "The advancement of 7XXX series aluminum alloys for aircraft structures: a review," Metals, vol. 11, no. 51, 2021.

[5] H. Che, X. Jiang, N. Qiao, and X. Liu, "Effects of Er/Sr/Cu additions on the microstructure and mechanical properties of Al-Mg alloy during hot extrusion," Journal of Alloys and Compounds, vol. 708, pp. 662-670, 2017.

[6] K. Zhang, K. Marthinsen, B. Holmedal, T. Aukrust, and A. Segatori, "Through thickness variations of deformation texture in round profile extrusions of 6063-type aluminium alloy: experiments, FEM and crystal plasticity modelling," Materials ence \& Engineering A, vol. 722, no. 11, pp. 20-29, 2017.

[7] J. Zhao, J. Tan, Y. Deng, and J. Zhang, "Effect of strain rate on the recrystallization mechanism during isothermal compression in 7050 aluminum alloy," Materials ence and Engineering: A, vol. 734, pp. 120-128, 2018.

[8] G. Chen, C. Ren, Z. Ke, J. Li, and X. Yang, "Modeling of flow behavior for 7050-T7451 aluminum alloy considering microstructural evolution over a wide range of strain rates," Mechanics of Materials, vol. 95, pp. 146-157, 2016.

[9] J. Li, Z. Xie, S. Li, and Y. Zang, "Modeling on dynamic recrystallization of aluminium alloy 7050 during hot compression based on cellular automaton," Journal of Central South University, vol. 23, no. 3, pp. 497-507, 2016.

[10] S. Q. Huang, Y. P. You, and L. Chao, "Simulation of dynamic recrystallization for aluminium alloy 7050 using cellular automaton," Journal of Central South University, vol. 16, pp. 0018-0024, 2009.

[11] K. R. Cardoso, D. N. Travessaa, W. J. Botta, and A. M. JorgeJr, "High Strength AA7050 Al alloy processed by ECAP: microstructure and mechanical properties," Materials Science and Engineering: A, vol. 528, no. 18, pp. 5804-5811, 2011.

[12] L. Yunzhong, L. Zhilong, and G. Caixin, "Deformation behavior and microstructure evolution of 7050 aluminum alloy during semi-solid state compression process," Acta Metallurgica Sinica, vol. 49, no. 12, pp. 1597-1603, 2013.

[13] R. Branco, J. D. Costa, and L. P. Borrego, "Effect of strain ratio on cyclic deformation behaviour of 7050-T6 aluminium alloy," International Journal of Fatigue, vol. 129, Article ID 105234, 2019.

[14] G. Wei, L. Jinghuan, and W. Yide, "Effect of grain size and taylor factor on the transverse mechanical properties of 7050 aluminium alloy extrusion profile After over-aging," Acta Metallurgica Sinica, vol. 51, no. 1, pp. 51-59, 2016.

[15] J. Li, "Comparative investigation on the modified ZerilliArmstrong model and Arrhenius-type model to predict the elevated-temperature flow behaviour of 7050 aluminium alloy," Computational Materials Science, vol. 71, no. 3, pp. 56-65, 2013.

[16] F. J. Humphreys and M. Hatherly, Recrystallization and Related Annealing Phenomena, p. 658, Pergamon, Oxford, UK, 2004.

[17] G. Wei, "Study on microstructure and mechanical properties during extrusion and heat treatment process of 7050 high strength aluminum alloy with large cross-section," Doctoral Thesis, School of Materials Science and Engineering, University of Science and Technology Beijing, Beijing, China, 2015.

[18] G. Yifei, L. Xinbang, and D. Xinglin, "Metallic materialstensile testing-Part 1: Method of test at room temperature," vol. 20, China National Standardizing Committee, Beijing, China, 2012, ISO/TC 164/SC 1.

[19] Y. Wua, C. Liu, H. Liao, J. Jiang, and A. Ma, "Joint effect of micro-sized Si particles and nano-sized dispersoids on the flow behavior and dynamic recrystallization of near-eutectic Al-Si based alloys during hot compression," Journal of Alloys and Compounds, vol. 856, Article ID 158072, 2020.

[20] K. G. Basavakumar, M. Pudukottah, and M. Chakraborty, "Influence of grain refinement and modification on microstructure and mechanical properties of $\mathrm{Al}-7 \mathrm{Si}$ and Al-7Si-2.5Cu cast alloys," Materials Characterization, vol. 59, no. 3, pp. $283-289,2008$.

[21] H. Utsunomiya, K. Hatsuda, T. Sakai, and Y. Saito, "Continuous grain refinement of aluminum strip by conshearing," Materials Science and Engineering A, vol. 372, no. 1-2, pp. 199-206, 2004.

[22] L. Lin, Z. Kui, L. Xinggang, L. Yongjun, M. Minglong, and S. Guoliang, "Microstructure and mechanical properties of Mg-Mn-Zn magnesium alloy with different Zn contents," Chinese Journal of Rare Metals, vol. 40, no. 6, pp. 552-558, 2016. 